Коновалова Ирина Александровна, Горлова Елена Борисовна, Шепелев Данил Романович

\title{
СТРАТЕГИЧЕСКИЕ ПОДХОДЫ К ОБОСНОВАНИЮ СТРАТЕГИЙ УСПЕШНОГО РАЗВИТИЯ БАНКОВСКИХ УЧРЕЖДЕНИЙ С УЧЕТОМ ЭКОНОМИЧЕСКИХ И ИНСТИТУЦИОНАЛЬНЫХ ФАКТОРОВ
}

В статье рассиатриваются параметры создания правильной банковской стратегии, черты и факторы, обусловленные конструктивностью стратегии экономического поведения банковской системы на экономическом рынке, проводится анализ подходов кустановлению стабильности финансовых организаций и структурных составляюиих их финансового расположения, исследуются ноансы экономической стабильности банковских учреждений как условия конкурентоспособности, выявляются условия, положительно и отрицательно влияюцие на финансовую устойчивость финансовых учреждений.

Ключевые слова: банковская система, коммерческие банки, банковская концепчия, финансовая стабильность, финансы, кредит, финансовая устойчивость, банковская среда, финансовые риски, устойчивый банк, банковская работа.

\section{Irina Konovalova, Elena Gorlova, Danil Shepelev STRATEGIC APPROACHES TO JUSTIFY STRATEGIES FOR SUCCESSFUL DEVELOPMENT OF BANK INSTITUTIONS TAKING INTO ACCOUNT ECONOMIC AND INSTITUTIONAL FACTORS}

The article discusses the parameters of creating the right banking strategy, features and factors, A constructive strategy for the economic behaviour of the banking system in the economic market, Analysis of approaches to establishing the stability of financial organizations and structural components of their financial location, The muances of economic stability of banking institutions as conditions of competitiveness are investigated, conditions are identified, Positively and negatively affecting financial stability of financial institutions, the distinctive characteristics of functional expectations of various participants of financial and credit relations for financial stability and stability are touched upon.

Key words: banking system, commercial banks, banking concept, financial stability, finance, credit, financial sustainability, banking environment, financial risks, sustainable bank, banking work.

Bведениe / Introduction. Банковская система на современном этапе является ключевым инструментом, использование которого дает возможность приспособиться к нынешним условиям рыночной экономики. Основой любой банковской системы выступают коммерческие банки (КБ). КБ способны влиять на разные сферы экономики нашей страны, в том числе на финансовую, посредническую и другие.

Стабильность банковской стратегии зависит непосредственно от характера управленческих решений. Данные решения, в свою очередь, указывают на поэтапность ее совершенствования. Существует ряд факторов, которые влияют на использование и разработку правильной, экономически-эффективной стратегии поведения участников банковского сектора на рынке финансовых услуг. Сюда относится конкуренция в сфере предоставления финансовых услуг, позитивное воздействие новаторской сферы и инноваций, проведения реформ в финансовом и экономическом секторе, стагнация в финансовой структуре 
Отмеченный ряд явлений отображает влияние на трансформацию общественно-финансовой сферы деятельности, где банковские учреждения ведут свою деятельность.

Сегодня одним из основных направлений финансово-экономических институтов выступает создание единых положений к определению устойчивого формирования КБ как ключевых компонентов банковской стратегии. Стабильность и эффективность функционирования банковской системы относится к числу взаимосвязанных признаков, являющихся ключевыми условиями, которые нужны для изучения модели развития банковской стратегии. Вместе с вышеперечисленными факторами ключевыми параметрами построения банковской стратегии выступают:

- уровень надежности кредитных организаций;

- риски и степень их значимости;

- оптимальный диапазон и ключевое свойство услуг финансового характера;

- срок проведения актуального цикла новой продукции в банковской сфере.

Maтериалы и методы / Materials and methods. В качестве материалов и методов решения задач исследования использовались информационно-аналитический подход к развитию банковской системы в мире и в России; сравнительный анализ функциональных ожиданий разнообразных участников финансово-кредитных отношений для всестороннего раскрытия темы.

Pезультаты и обсужжение / Results and discussion. Ключевой чертой эффективной стратегии устойчивого формирования и развития коммерческой структуры выступает финансовая стабильность. В этом случае необходимо выделить положение рынка услуг экономического характера, В этой среде осуществляется работа финансового и кредитного учреждения. Формируется возможность оперативного принятия решения в соответствии с изменениями состояния не только внутренних, но и внешних рыночных взаимоотношений.

Исследование отечественной научной литературы позволяет нам отметить существование множества различных подходов к определению первичной, базовой, структуры стабильности финансовой организации, отображающих весь спектр аспектов отмеченного движения в рыночной экономике. Эти аспекты определяется, в свою очередь, различными взаимосвязями стадий воспроизводственного движения, а также огромной степенью неопределенности функционирования финансово-кредитных организаций, которые находятся сегодня под большим влиянием перемен и учащения действий глобализации экономики.

Большое количество взаимосвязей, существующих между экономическими и отраслевыми капиталами, четко прослеживается в положении стабильности банков и является одним из ключевых элементов их эволюции.

Проблеме надежности и стабильности финансовых организаций в экономическом плане посвящено большое количество трудов отечественных и зарубежных исследователей, которые рассматривают надежность и стабильность банковской системы, как правило, в качестве высококачественных показателей финансового потенциала банковского учреждения.

В зарубежной литературе стабильность финансовых организаций обусловливаются свойственными формами построения финансовых и кредитных институтов в современных условиях рыночной экономики. Однако в условиях изменяющихся ситуаций всемирной экономической системы исследование и разрешение сложных задач в сфере банковских услуг нуждается в адекватном подходе в конкретной ситуации.

Отечественные экономисты, такие как Фетисов, Ларионова и Панова, основывают свои точки зрения на систематическом аспекте, в соответствии с которым обеспечение устойчивости экономики в сфере банковских услуг является поддерживает сбалансированность финансовых показателей банка. Исследователи считают, что стабильным будет выступать именно тот банк, который является финансово устойчивым. Однако в данном случае их внимание акцентируется на том, что финансовая устойчивость банков и финансовых организаций является отдельно 
взятым явлением, ввиду того что она представляет собой натуральный, качественный показатель состояния банковских организаций, осуществляющих свою деятельность в условиях постоянных трансформаций - со стабильного состояния в устойчивое. При этом стоит отметить, что финансово стабильный субъект хозяйствования не может постоянно работать устойчиво, а значит, можно сказать, что устойчивость банковского учреждения следует отнести к числу суммарных характеристик, в состав которых входит исследование и оценка взаимоотношений субъекта хозяйствования с субъектами межнациональной и локальной сферы, а также процедура выявления внутренних запасов и определение показателя его платежеспособности.

По нашему мнению, устойчивость банковской сферы является фундаментальным аспектом, обладающим рядом особенностей, сходных с надежностью банковской системы. Если рассматривать понятие «надежность», необходимо отметить зависимость данного явления от эффективной стабильности деятельности финансовых организаций. В связи с этим КБ должен применять унифицированный стандарт обслуживания и понимания потребителей и акционеров как социально ориентированного регулирующего механизма. Соответственно, по мнению потребителей банковских услуг, высоконадежные банковские и финансовые организации строят свою деятельность на предоставлении качественных услуг, полностью соответствующих клиентским ожиданиям. Акционеры данных организаций инвестируют свои средства исключительно в надежные финансовые учреждения, ожидая, что субъект их инвестиций в будущем станет эффективным источником получения дохода, превышающего прибыль от вложения средств в другие отрасли.

Менеджеры банковской организации придерживаются немного другой точки зрения. Данный штат сотрудников заинтересован прежде всего в стабильной работе, а также в соответствующей оплате их труда.

Для общественности прочность может обеспечиваться Центральным банком РФ. Данное учреждение заботится не только о соблюдении интересов потребителей банковских услуг и биржевых маклеров, но и банковской стратегии. Надежная финансовая организация, по мнению общественности, должна обязательно поддерживать равновесие между интересами финансового учреждения и потребителями ее услуг.

Надежный банк представляет собой финансовую организацию, которой доверяют потребители банковских услуг и которая гарантирует реализацию интересов клиентов и вкладчиков. Деятельность таких банков базируется на принципах взаимовыгодных отношений.

В результате проведенного анализа мы получили возможность выделить ряд целевых установок, имеющих непосредственное отношение к деятельности банковских организаций. Для потребителей банковских услуг экономическая стабильность банка является одним из главных показателей его деятельности. Поэтому с точки зрения клиентов банков стабильность финансовой организации должна проявляться непосредственно в том, что Центральный банк РФ выполнит перед ними все обязательства четко в установленные сроки и в соответствующем размере.

По мнению инвесторов и акционеров, основным показателем стабильности банка является увеличение его рыночной стоимости, а также устойчивость финансовой организации. Для сотрудников банковских учреждений стабильность банка отражается в высоких позициях рейтингов, а также в высоком уровне их конкурентоспособности.

Институты государственного регулирования уделяют наибольшее внимание непосредственно охране интересов потребителей банковских услуг. Для достижения рассмотренных выше целей любое из известных банковских учреждений использует любую доступную для него информацию, которая позволяет ему выявить ключевые характеристики, отвечающие непосредственно за безопасность и экономическую стабильность организации.

Стратегические ожидания суббъектов, принимающих участие в финансово-кредитных отношениях, приведены в таблице. 
Отличительные признаки функциональных ожиданий разнообразных участников финансово-кредитных отношений к «финансовой устойчивости», «надежности» и «стабильности» банка

\begin{tabular}{|c|c|c|c|}
\hline $\begin{array}{l}\text { Субъект } \\
\text { финансово- } \\
\text { кредитных } \\
\text { отношений }\end{array}$ & $\begin{array}{c}\text { Финансовая } \\
\text { стаб̆льность }\end{array}$ & Надежность & Устойчивость \\
\hline $\begin{array}{l}\text { Клиенты и } \\
\text { кредиторы }\end{array}$ & $\begin{array}{l}\text { Выполнение банковской } \\
\text { организацией обязательств } \\
\text { перед ними в срок и в } \\
\text { полном объеме }\end{array}$ & $\begin{array}{l}\text { Предоставление } \\
\text { банковской } \\
\text { организацией продуктов } \\
\text { и услуг с ожидаемыми } \\
\text { характеристиками и } \\
\text { ассортиментом }\end{array}$ & $\begin{array}{l}\text { Возможность противостоять } \\
\text { и преодолевать влияние } \\
\text { негативных внутренних и } \\
\text { внешних факторов }\end{array}$ \\
\hline Акционеры & $\begin{array}{l}\text { Рост рыночной стоимости } \\
\text { бизнеса наряду с } \\
\text { устойчивостью кредит-ной } \\
\text { организации }\end{array}$ & $\begin{array}{l}\text { Получение достаточной } \\
\text { нормы прибыли на вло- } \\
\text { женные средства }\end{array}$ & $\begin{array}{l}\text { Диапазон состояний, } \\
\text { в рамках которого } \\
\text { поддерживается } \\
\text { сбалансированность } \\
\text { развития банка }\end{array}$ \\
\hline Менеджеры & $\begin{array}{l}\text { Устойчивое развитие } \\
\text { банка в динамичной сре- } \\
\text { де и долговременной его } \\
\text { конкурентоспособности }\end{array}$ & $\begin{array}{l}\text { Сохранение работы и } \\
\text { достойной заработной } \\
\text { платы }\end{array}$ & $\begin{array}{l}\text { Диапазон состояний, } \\
\text { в рамках которого } \\
\text { поддерживается финансовая } \\
\text { устойчивость банка }\end{array}$ \\
\hline $\begin{array}{l}\text { Государственный } \\
\text { регулятор }\end{array}$ & $\begin{array}{l}\text { Выполнение возложенных } \\
\text { функций от имени } \\
\text { общества, защите инте- } \\
\text { ресов кредиторов и } \\
\text { инвесторов }\end{array}$ & $\begin{array}{l}\text { Соблюдение интересов } \\
\text { вкладчиков, инвесторов } \\
\text { и банковской системы в } \\
\text { целом }\end{array}$ & $\begin{array}{l}\text { Сохранение запаса } \\
\text { финансовой прочности банка }\end{array}$ \\
\hline
\end{tabular}

Важнейшей характеристикой устойчивости банка является ее структурная многосложность, обусловленная множеством определяющих ее факторов. В первую очередь стоит отметить такой структурный элемент, как организационно-структурная устойчивость. Основным фактором данной составляющей является организационно-технологическое разделение отдельно взятых видов деятельности. Дифференциация видов деятельности осуществляется на базе функционально-технологических документов. Данные документы регулируют деятельность банковского учреждения в рамках как его организационной структуры, так и выполняемых функций.

Следовательно, функционирование банковского учреждения происходит на базе регулярно изменяющихся условий, оказывающих существенное воздействие на финансовую устойчивость банка. Поэтому банк должен акцентировать все свое внимание на разработке и реализации организационных и экономических мероприятий, комплексной оценке финансовой и экономической политики, улучшении информационного обеспечения и разработке и совершенствовании банковских технологий.

Проведенное нами исследование, позволило выявить условия, положительно и отрицательно влияющие на финансовую устойчивость финансовых учреждений. Среди них выделим: макро-, мезо- и микроэкономический характер, глобального и государственного уровней, общего состояния экономики и финансово-кредитной отрасли, факторы отдельных бизнес-процессов КБ. В итоге разнонаправленного действия аспектов, влияние которых на банки имеют личные векторы, создается разнообразие приоритетов стратегии по управлению финансовой устойчивостью.

В методологическом ракурсе анализ условий и факторов, оказывающих влияние на устойчивость банковской системы и КБ как элементов в динамичной среде современного рынка, опирается на качественное различие влияния макроэкономических аспектов на отдельный банковский 
институт в совокупности с микроэкономическими положениями, общность банков и банковских систем в целом. Факторы, которые провоцируют разрушение банковской системы, могут использоваться для реализации нынешних интересов отдельного банковского учреждения, и наоборот. Значение институционального подхода к анализу устойчивости банковской системы состоит в установлении взаимообусловленности двух уровней - ЦБ и КБ, функций и институциональной базы, которые соответствуют каждой составляющей банковской системы, в том числе в выявлении макроэкономических условий и аспектов работоспособности банковской системы как единой структуры государственной экономики. Банковский сектор в поступательном развитии находится под влиянием определенного объема аспектов, характерных для работы банковской системы в целом (институциональная основа, модель построения, межуровневые отношения, регулятивные функции).

Отдельное воздействие на устойчивое совершенствование российских банковских учреждений оказывают разрабатываемые Центральным банком РФ вместе с Правительством направления государственной денежно-кредитной политики и инструментария, необходимого для ее претворения в жизнь, отображает обобщенные условия финансовой устойчивости банка и аспекты, оказывающие воздействия на ее уровень.

Благодаря проведению SWOT-анализа нам удалось выявить наиболее сильные и наиболее слабые стороны деятельности банковского учреждения, установить возможные угрозы внешней среды и благоприятные положения, по отношению к среднеотраслевым показателям.

На базе проведенного комплексного анализа таких терминов, как «экономическая стабильность», «безопасность» и «устойчивость» нами были сделаны следующие выводы.

При исследовании процессов деятельности банковского учреждения как части всей системы целесообразно прибегать к использованию диалектического определения потребности и случайности. Существующие временные взаимосвязи принято считать неустойчивыми, поскольку они практически не поддаются численному анализу. Следовательно, «экономическая стабильность» на данный момент пребывает в стадии диалектического развития. Экономическая стабильность финансовой организации может рассматриваться в следующих скоротечных понятиях: стабильность как резерв, течение и прогноз. В отмеченной взаимосвязи информативной базой для установления уровня экономической стабильности предусмотрены стабильные и динамические балансы банковской организации с отмеченной периодичностью их формирования. Экономическая стабильность банковской организации определяется достаточно высоким уровнем собственных денежных средств, ликвидностью и рентабельностью.

Под финансовой стабильностью принято понимать систематический процесс, включающий в себя установление и систематизацию, а также подбор показателей текущей и перспективной оценки.

Заключение / Conclusion. Система управления реализацией стратегии формируется на основе существующей в Банке организационной структуры и управленческих механизмов. Территориальные банки станут ответственными за обеспечение и успех внедрения стратегии в своих регионах и будут отвечать за внедрение по курируемым направлениям бизнеса и функциональным областям. Данная структура управления реализацией стратегии позволит обеспечить максимальный учет региональной специфики и снизит риски внедрения. Для обеспечения оптимального распределения ответственности и однозначного понимания роли каждого из подразделений в реализации инициатив будет сформирован каскад планов, при котором общий план реализации будет детализирован до уровня каждого территориального банка, что позволит координировать действия всех участников реализации стратегии и выделить централизованные общебанковские мероприятия и инициативы. Важным условием успешной реализации проектов станет активное вовлечение территориальных банков в процесс планирования, которое позволит в полной мере учесть региональную специфику и максимально использовать обмен опытом и идеями между регионами. 
В ходе реализации стратегии будут применяться многоуровневая система мониторинга реализации программы, охватывающая все регионы и уровни банковской иерархии, и соответствующая ей система контрольных показателей. В банке должна быть сформирована сильная команда, которая будет способна поддерживать высокий профессиональный авторитет банка и давать правильные и нужные советы клиентам. Данные стратегические факторы обеспечивают успех банковской деятельности.

Существуют также и другие оперативные факторы успеха банковской деятельности. Банк может добиться успеха, когда его политика ориентирована на определенные ценности, которые, в свою очередь, приводят к достижению желаемого результата. Среди таких оперативных факторов выделяют ориентацию банка на клиента. Принципом работы банка должно быть то, что клиент всегда прав. Когда банку удается придерживаться такого принципа, его работу можно считать удачной. Важнейший оперативный фактор успеха деятельности банка - это стратегия затрат и снижение стоимости банковских услуг. Банкам необходимо преодолеть себя и создать механизм, обеспечивающий экономию производимых затрат и снижение себестоимости банковского продукта. Создание информационных систем, сотрудничество с иностранными банками и организация внутреннего банковского аудита, переход на новую технологию банковского обслуживания являются факторами, которые обеспечивают успех банка.

Проведенные исследования дают возможность разработать стратегические ориентиры стабильного развития экономики и успешного развития банковских учреждений с учетом экономических и институциональных факторов.

\section{ЛИТЕРАТУРА И ИНТЕРНЕТ-РЕСУРСЫ}

1. Банковское право: учеб. для бакалавров / Д. Г. Алексеева, А. Г. Гузнов, Л. Г. Ефимова и др. ; отв. ред. Л. Г. Ефимова, Д. Г. Алексеева. - 2-е изд., перераб. и доп. - Москва : Проспект, 2019. - 608 с. - Текст : непосредственный.

2. Занин, А. С. Центральный банк России как регулятор страхового рынка / А. С. Занин // Финансовое право. - 2017. - № 11. - С. 43-48. - Текст : непосредственный.

3. Козынкин, И. В. Центральный банк Российской Федерации как регулятор и одновременно с этим участник финансового рынка / И. В. Козынкин // Молодой ученый. - 2018. - № 35. - С. 60-63. Текст : непосредственный.

4. Шепелев, Д. Р. Оценка состояния банковской системы России в условиях экономической нестабильности / Д. Р. Шепелев // Университетская наука - региону : материалы VII ежегодной научно-практической конференции Северо-Кавказского федерального университета преподавателей, студентов и молодых ученых / под ред. Л. И. Ушвицкого, А. В Савцовой. - 2019. - С. 116-119. - Текст : непосредственный.

\section{REFERENCES AND INTERNET RESOURCES}

1. Bankovskoe pravo (Banking law): ucheb. dlja bakalavrov / D. G. Alekseeva, A. G. Guznov, L. G. Efimova i dr. ; otv. red. L. G. Efimova, D. G. Alekseeva. - 2-e izd., pererab. i dop. - Moskva : Prospekt, 2019. - 608 s.

2. Zanin, A. S. Central'nyj bank Rossii kak reguljator strahovogo rynka (Central Bank of Russia as a regulator of the insurance market) / Zanin A. S. // Finansovoe pravo. - 2017. - № 11. - S. 43-48.

3. Kozynkin, I. V. Central'nyj bank Rossijskoj Federacii kak reguljator i odnovremenno s jetim uchastnik finansovogo rynka (Central Bank of the Russian Federation as a regulator and at the same time a participant of the financial market) / I. V. Kozynkin // Molodoj uchenyj. - 2018. - № 35. - S. 60-63.

4. Shepelev, D. R. Ocenka sostojanija bankovskoj sistemy Rossii v uslovijah jekonomicheskoj nestabil'nosti (Assessment of the state of the banking system of Russia in the conditions of economic instability) / D. R. Shepelev // Universitetskaja nauka - regionu : materialy VII ezhegodnoj nauchno-prakticheskoj konferencii Severo-Kavkazskogo federal'nogo universiteta prepodavatelej, studentov i molodyh uchenyh / pod red. L. I. Ushvickogo, A. V Savcovoj. Stavropol', 2019. - S. 116-119. 


\section{СВЕДЕНИЯ ОБ АВТОРАХ}

Коновалова Ирина Александровна, кандидат экономических наук, доцент кафедры экономики и внешнеэкономической деятельности ФГАОУ ВО «Северо-Кавказский федеральный университет». E-mail: konovalova.iris@yandex.ru

Горлова Елена Борисовна, кандидат педагогических наук, доцент кафедры «Социальных технологий» Института образования и социальных наук Северо-Кавказского федерального университета

Шепелев Данил Романович, студент, направление 38.04.01 Экономика, направленность (профиль) «Экономика фирмы», ФГАОУ ВО «Северо-Кавказский федеральный университет», E-mail: danishepelev(a) yandex.ru

\section{INFORMATION ABOUT AUTHORS}

Irina Konovalova, candidate of economic Sciences, associate Professor of Economics and foreign economic activities, North-Caucasian Federal University. E-mail: konovalova.iris@yandex.ru

Elena Gorlova, candidate of pedagogical Sciences, associate Professor of the Department of «Social technologies» of the Institute of education and social Sciences of the North Caucasus Federal University

Danil Shepelev, student, direction 38.04.01 Economics, direction (profile) «Economics of the company», NORTH Caucasus Federal University» E-mail: danishepelev@yandex.ru 